\title{
PROSPECTS AND CHALLENGES IN DEVELOPING 'JAPANESE STUDIES' PROGRAM IN BANGLADESH: LESSONS FROM UNIVERSITY OF DHAKA ${ }^{1}$
}

\author{
Md. Saifullah Akon ${ }^{2}$ and Dilruba Sharmin ${ }^{3}$
}

\begin{abstract}
Japanese Studies has entered a booming period in Bangladesh where the growing demand for knowledge on Japan, particularly Japanese development experience, society, and culture, has intensified. Besides, the increasing number of Japanese companies and opportunities to work in Japan so far is conducive to the increasing number of students in the Japanese language. Considering the given facts, academic institutions of Bangladesh need to initiate 'Japanese Studies' programs to produce 'Japanologists'-contextual and transitional expertise. The larger goal of this study is to identify the major prospects and challenges and consider the future directions for the Japanese Studies program. The paper intends to think alternatively beyond the 'ivory tower' mindset of a large number of Bangladeshi students as well as academicians and show the prospects of Japanese Studies with sustainable employment opportunities through industry-academia collaboration. The methods and equipping tools employed in this paper include lexical scrutiny and contextual analysis under the qualitative research method to analyse the current state of knowledge and pedagogical development. Presenting the number of stumbling blocks of the Japanese Studies program in Bangladesh, the paper finally demonstrates the program's future as an academic discipline. It ends with possible suggestions towards success in producing Japanologists to strengthen Bangladesh-Japan bilateral relations.
\end{abstract}

Keywords: area studies, Japanese studies, multidiscipline, Japanologists, Bangladesh-Japan relations

\section{INTRODUCTION}

Japanese Studies is a thriving academic field worldwide, one in which the number of students is increasing and hundreds of research works are published annually. ${ }^{4}$ The study of Japan has become a wide-ranging, multidisciplinary and interdisciplinary field of studies in which a person might specialize in Japanese history, literature, society, politics, culture, arts, as well as language. ${ }^{5}$ To some extent, based on the definition, Japanese Studies is considered as an Area of Studies. Having multidisciplinary and transdisciplinary qualities, Japanese Studies taking huge advantages.

\footnotetext{
${ }^{1}$ Article info: Received: 4 October 2021; Acceptance: 10 November 2021; Published: 15 December 2021.

${ }^{2}$ First and Corresponding Author: Md. Saifullah Akon, Department of Japanese Studies, Faculty of Social Sciences, University of Dhaka, Dhaka 1000, Bangladesh. Email: msakon72@gmail.com.

${ }^{3}$ Second Author: Dr. Dilruba Sharmin, Department of Japanese Studies, Faculty of Social Sciences, University of Dhaka, Dhaka 1000, Bangladesh. Email: dsharmin.jc@ac.bd

${ }^{4}$ See also Andreas Mehler, "Comparative Area Studies," in Matthias Middell ed., The Routledge Handbook of Transregional Studies, (London: Routledge, 2018), 167.

5 See also Jin Sato, "Research at a Distance: Area Studies in the Post-Pandemic Era," International Journal of Asian Studies 17, no. 2, (2020): 105-108.
} 
On the other hand, the Japanese Studies program as a discipline is just passing its infancy in Bangladesh. At the time of independence in 1971, there was hardly any provision in the educational institutions or universities for the study of 'area studies '. In the post-independence period, language program was initiated by establishing several language institutions or training centers. Beyond language education, no multidisciplinary area studies were developed in social sciences and humanities. During that time, area studies were largely limited to language education. However, understanding the importance of area studies , particularly Japanese Studies, Dhaka University has initiated to establish a full fledge multidisciplinary department in social sciences in 2017, called the Department of Japanese Studies (DJS).

The quality and quantity of the Japanese Studies program in Bangladesh is influenced by different factors including Bangladesh-Japan bilateral relations, Japanese engagement and investment in Bangladesh, and academic development of Japanese Studies. Since the engagement of Japan with Bangladesh and the Japanese skyrocketing investment manifold intensified, students are getting hope about Japanese Studies. Besides, Japan is the only country in Bangladesh that started to contribute to promoting knowledge and academic activities. The demand has become more and more pressing today.

In terms of study on Japan, a big question arises on why we should study Japan. For the past few years, Japan has been considered as the sole development partner of Bangladesh, the foundation of which was laid by the 'Special Goodwill Envoy' sent by Japan in the post-independence period of Bangladesh. In 2014, the 'Japan-Bangladesh Comprehensive Partnership Treaty' between the two friendly countries further accelerated the continuity of this development cooperation. In recent times, the number of Japanese companies in Bangladesh and their Foreign Direct Investment (FDI) is increasing over the years. Current Japanese mega projects like 'Bay of Bengal Industrial Growth Belt (BIG-B), Dhaka Metro Rail- are a testament to the harmony and development partnership between the two countries. These Japanese companies and mega projects are offering lucrative employment opportunities. Besides, labour migration to Japan has increased rapidly. These opportunities, provided by Japan, could help Bangladesh to gain its sustainable development goals (SDGs).

However, the paper proposes the prospects of the developments of Japanese Studies as an academic discipline in Bangladesh. The paper is constructed in four major sections. The first section demonstrates the current status of the Japanese Studies program in Bangladesh. The second section mainly shows the ample opportunities provided by the Japanese Studies program by answering the said question on why we should study Japan. The third section of the paper focuses on the current major challenges to developing Japanese Studies as a discipline in academic institutions. In the final section, we suggest some policy prescriptions to both Bangladesh and the Japanese side as key actors to promote the Japanese Studies program in Bangladesh.

\section{METHODOLOGY}

The study has been conducted following a qualitative research approach, a popular research method in social sciences, which is exploratory and descriptive in nature. To get the current state of the Area studies and Japanese Studies program in Bangladesh, the study involves and relies heavily upon oral questioning to different respondents, who are being able and willing to give accurate information on the extant study ${ }^{6}$. The study follows in-depth interviews (IDIs) which explore the thoughts and perspectives of a small number of respondents on area studies and Japanese Studies programs ${ }^{7}$. Besides, the study also takes focus group discussions (FGD) with different university students to gather information.

\footnotetext{
${ }^{6}$ Glynis M. Breakwell, Interviewing: Problems in Practice, (London: Blackwell, 1990), 12.

${ }^{7}$ Carolyn Boyce, "Conducting in-depth Interviews: A Guide for Designing and Conducting In-Depth Interviews for

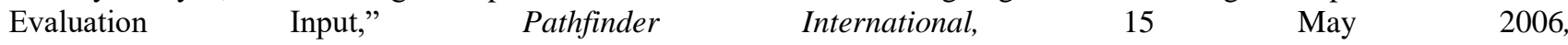
https://donate.pathfinder.org/site/DocServer/m_e tool_series_indepth_interviews.pdf;jsessionid=00000000.app20015b? NONCE_TOKEN=15965777B6F9B194066D1C6E161E9EE0
} 


\section{Data Collection}

Data has been collected from both primary and secondary sources. Three different stakeholders have been selected for IDIs: academicians who are related to the Japanese Studies program or East Asian Studies program, Japan-related corporate sectors, mainly Japan-Bangladesh Chamber of Commerce and Industry (JBCCI) and Japan External Trade Organization (JETRO), and students from both public and private universities. A semi-structured, with a more open-ended question, was used for the IDIs. Besides, a focus group discussion (FGD) was conducted among 20 students where 13 students were from public universities and another 7 students were from private universities. In terms of ethical consideration, respondents from IDIs, and FGDs were briefed about the research purpose and their consent was taken for audiotape and references. Besides, to understand the existing knowledge on area studies, several secondary information have been collected from different sources including books, journals, websites, etc., and been examined with the primary data.

\section{THE STATE OF 'JAPANESE STUDIES’ PROGRAM IN BANGLADESH}

The idea of discipline is changing over time globally. Over the last decade, the importance of area studies has increased particularly in academia. To define the area studies, Masao Miyoshi and H. D. Harootunian argued that, "area studies has been gradually transformed from the status of supplying information on potential enemies to national interest and security to highly visible public relations services devoted to providing 'balanced' images of donor societies to an educated segment of the American public, and certainly to that part of the population who will become experts in the formation of public opinion" $"$. As a field of area studies, the Japanese Studies program has been developed in more than hundreds of academic institutions, i.e. Japanese Studies program at University of Cambridge in UK, National University of Singapore in Singapore, Jawaharlal Nehru University in India, University of Sydney in Australia, etc. According to Gaitanidis, ${ }^{9}$ since the beginning of the $21^{\text {st }}$ century, more universities have opened different courses under the 'Japanese Studies' program with renaming the courses like Japanese Literature or Japanese History.

Japanese Studies program as a discipline in Bangladesh is still in its formative stage. It could be seen from two different perspectives: teaching and research ${ }^{10}$. In terms of teaching, though Bangladesh has been observing 50 years of independence, the country's no higher institutions developed any Japanese Studies department or any other area studies until 2017. Since its introduction in 1972, Japanese language education has grown in popularity, while Japanese Studies as a social science discipline are much lagging behind. So far, only one university in Bangladesh has been teaching Japanese Studies as a multidisciplinary program under social sciences as a major for undergraduate courses. Apart from that, only 8 universities are providing Japanese language certificates under their language institutions. However, to discuss the current situation of learning the Japanese Studies program in Bangladesh, two broad fields should be analysed: a) 'Japanese Studies' as a multidisciplinary academic discipline and b) Japanese Language education.

\footnotetext{
${ }^{8}$ Ioannis Gaitanidis, "Critique of/in Japanese Studies: An Introduction to the Special Issue”, (paper presented at the British Association for Japanese Studies Conference, Chiba University, Japan, 27-28 May 2017), https://www.researchgate.net/publication/332142994_Critique_ofin_Japanese_Studies_An_Introduction_to_the_Special_ Edition

${ }^{9}$ Ioannis Gaitanidis, “Jobbing as Methodology: Victor T. King's Involvement with Area Studies and Some Implications for Japanese Studies and Beyond," in Arun Shyam ed., Boneo and Sulawesi: Indigenous Peoples, Empires and Area Studies, (London: Routledge, 2019), 177.

${ }^{10}$ Surichai Wun'Gaeo, “Japanese Studies in Southeast Asia: Problematic Trends and Challenges Ahead”, (paper presented at the Kyoto Conference on Japanese Studies, Kyoto, Japan, 25 March1996): 169-168.
} 


\section{Japanese Studies Program from the Multidisciplinary Lens}

Leaning 'Japanese Studies' is an interdisciplinary area where Japanese geography, culture, economics, government, and politics, language, and other aspects can be taught. Over the past two decades, Japanese Studies has been particularly successful in attracting students' attention. A detailed survey was undertaken to collect data to understand the state of learning the Japanese Studies program in the Bangladesh context. Data analysis revealed that only one public university has offered a 'Japanese Studies' program at honors and master's level, though some other universities offer only Japanese language learning programs.

The Department of Japanese Studies (DJS) of Dhaka University has started its journey in 2017 as a pioneer in this field. Currently, under the directives of the Faculty of Social Sciences of Dhaka University, the DJS offers a four-year Bachelor's degree, split into eight semesters, and a one-year Master's degree, split into two semesters which is totally multidisciplinary in nature. The primary goal of the courses offered by DJS under the rubric 'Japanese Studies' is to teach about Japan holistically including other principles of social sciences. DJS does not offer students only the basic knowledge on different Japan-related issues, rather it encourages and offers an environment of critical thinking for a deeper understanding of Japan from the various global phenomena. Besides, students of the DJS have Japanese language courses in each of their semesters which helps them to get advanced on the Japanese language.

\section{Japanese Language Education}

Due to the impact of globalization, the present world is a place to prove oneself capable and realize one's worth achievements by competing globally. In that case, knowing languages other than the mother tongue is to prove oneself a more deserving candidate. The history of learning the Japanese language in Bangladesh began in 1972 when Bangladesh has just achieved its independence. Initially, both the university and private language schools initiated the language training with a minimum number of students. From the 1990s, Bangladeshi students' attraction increases for Japanese higher studies and job searching purposes. Moreover, the Bureau of Manpower Employment and Training (BMET) introduced a Japanese language learning course in 27 technical training centers (TTC) across the country. These include Bangladesh Korea TTC (Mirpur), Seikh Fazilatinnesa Mujib Mahila TTC (Mirpur), Bangladesh Korea TTC (Chottogram), Khulna TTC, Rajshahi TTC, Tangpur TTC, Pabna TTC, Rangmato TTC, Bandar TTC, Bandar Tahiti, Bandar, Nilphamari TTC, Jessore TTC, Dinajpur TTC, Madaripur TTC, Narsingdi TTC, Magura TTC, Moulvibazar TTC, Prasad Kalyan Bhavan (Dhaka, Jamalpur TTC, Netrokona TTC. ${ }^{11}$

According to a survey study, conducted by the Japan Foundation in 2015,37 institutions ${ }^{12}$ in Bangladesh are providing Japanese language training. Chart 1 shows that the number of language institutions is increasing overtimes in Bangladesh considering the number of driving factors including scholarship, job opportunities primarily in Japan, working in Japanese companies in Bangladesh, etc.

\footnotetext{
${ }^{11}$ Mohammed Ansarul Alam, "JLE in Bangladesh-Recent Development and Challenges," in Arun Shyam ed., Japanese Language Education in South Asia: Issues and Challenges, (Dhaka: EFL University Publication, 2020), 18-19.

${ }_{12}$ Mohammed Ansarul Alam, "An Overview of Japanese Language Education in Bangladesh from the Perspective of Recent Progress in Japanese Language Education In South Asia,” Journal of the Institute of Modern Languages 23, (2012): 25.
} 


\section{Chart 1: Number of Japanese Language Institutions in Bangladesh ${ }^{13}$}

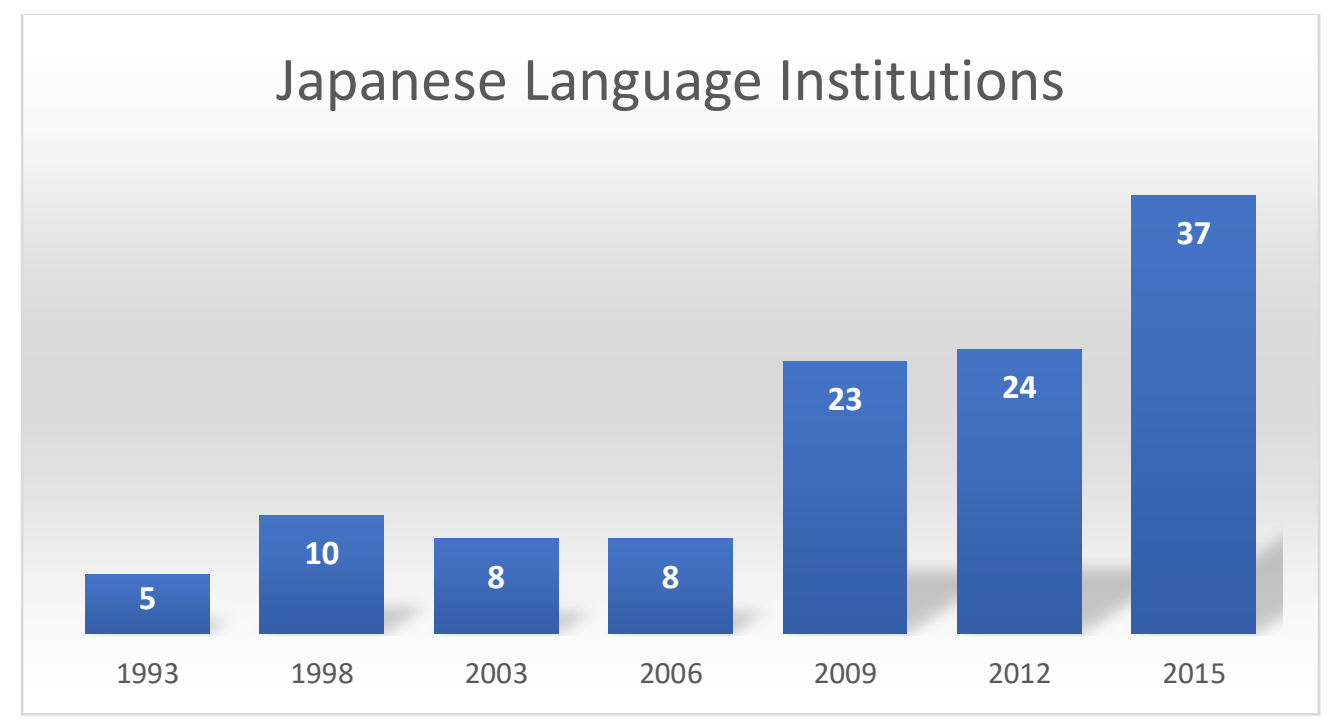

In 1972, a Japanese language course was started at Dhaka University, and a similar course was arranged inside the Japanese Embassy in the same year. Two years later, the Institute of Modern Language (IML) was established at Dhaka University. In the 1980s and 1990s, many Japanese language learning centers were established in the port city of Chittagong district of Bangladesh and also in the Rajshahi University. In the year 2001, JLPT (Japanese-Language Proficiency Test) exam was held for the first time in Dhaka and continues till today. One of the researches shows that only 452 students were learning the Japanese language in 1993, which increased to 2158 in $2015 .{ }^{14}$ Besides, JUAAB (Japanese Universities Alumni Association), established in 2000 with a dream to make a bonding among the Bangladeshi nationals who graduated from Japanese universities, has been working strongly to establish Japanese language learning courses in different methods.

\section{PROSPECTS FOR JAPANESE STUDIES PROGRAM IN BANGLADESH}

The significance of area studies has grown substantially within the social science framework. Area studies helps to analyse complex societal phenomena of a particular region. As a sub-field of Area studies, the Japanese Studies program has manifold intensified worldwide. The scope of Japanese Studies is broad and varies widely from country to country. Through this academic program, one can get professionalized knowledge of Japanese society, culture, business along with advanced training in the Japanese language. One of the basic goals of Japanese Studies program is increasing understanding and knowledge of Japan and to use the gained knowledge for the development in the host country. However, it is imperative to see how the study of Japan in Bangladesh could benefit Bangladesh.

\footnotetext{
${ }^{13}$ Mohammed Ansarul Alam, "JLE in Bangladesh-Recent Development and Challenges," 22.

${ }^{14}$ Ibid
} 


\section{Diffusion of Knowledge}

Area studies represent the epitome of inter-and multidisciplinary research ${ }^{15}$ and promote specialists in a particular country or region by 'inclination and training' ${ }^{16}$. As an area studies, the Japanese Studies program provides new material and new ideas. As a new academic field, scholars have been developed and legitimized new understandings and forms of knowledge ${ }^{17}$ which has yielded great advances in the subfields of the Japanese economy, politics, history, etc. The program implies more interactive cooperation of several disciplines for attaining a deeper understanding of Japan-related issues. It helps to produce a sea of empirical knowledge on Japan. In terms of diffusion of knowledge, the Japanese Studies program can help constitute a field of discussion ${ }^{18}$ in two diverse ways: multidisciplinary approach and Japanese language training.

By emphasizing a 'multidisciplinary lens', area studies is capable of conveying a full understanding of another nation, its society, culture, and other social mechanisms, which is generally obscure in other traditional disciplines in social sciences. Due to its multidisciplinary nature, the Japanese Studies program encompasses all academic disciplines in social sciences, i.e. History, Economics, Political Science, International Relations, Sociology, Geography, Law, etc. Apart from pure and applied sciences, according to Lesley Pitman, there is no limit to the subjects that can be included in area studies. ${ }^{19}$. Through the Japanese Studies program, one can broaden their interests and be able to understand Japan holistically by studying Japanese history, economics, political system, foreign policy, society, geography, anthropology, law, language, literature, etc. The Japanese Studies courses present certain characteristics that distinguish the new program from other disciplines and can help to draw comparative views on the peoples living in Bangladesh and Japan. Young scholars who are interested in Japanese Studies could acquire extensive experiences in Japanese development, business, governance, politics, literature, etc through this new academic discipline.

On the other hand, for better scholarly work in Japanese Studies, Japanese language skills are indispensable, which Hardacre ${ }^{20}$ describes as the heart and soul of Japanese Studies. Without proper knowledge and training in the Japanese language, it is no longer possible to do research and teach in the Japanese Studies field. Students of Japanese Studies have an opportunity to begin Japanese language study at an earlier age. However, indeed, the Japanese Studies program is nurturing critical thinking with skills and has been evoking the richness of critical thinking beyond the traditional education system.

\section{Economic Prospects}

Unemployment is a frequent problem in most of the developing and least developed countries. Given the relative job security, economic safety, and working environment, the young people of Bangladesh vie for public service jobs. Although government jobs are highly valued in Bangladesh, the number of vacancies is hardly accommodating the wide number of young graduates each year.

\footnotetext{
${ }^{15}$ Bo Petersson, “We Don't Do Areas Studies: Reflections on the Development of the Genre of Research from a Political Science Perspective," Forum of EthnoGeoPolitics 3, no. 2, (2015): 38.

${ }^{16}$ Rudra Sil, "The Survival and Adaptation of Area Studies," in Dirk Berg-Schlosser, Bertrand Badie and Leonardo Morlino eds., The SAGE Handbook of Political Science, (London: SAGE Publication, 2020), 268; Robert H. Bates, “Area studies and Political Science: Rupture and Possible Synthesis," Africa Today 44, no. 2, (1997): 124.

${ }^{17}$ Shabir Ahmad Khan, “Area studies : Nature and Scope," Central Asia Journal 82, no. 2, (2018,): 133.

${ }^{18}$ Michael D. Kennedy, “Globalizing Knowledge Through Area Studies,” The Journal of the International Institute 9, no. 1, (2001): 12-13.

${ }^{19}$ See also Lesley Pitman, Supporting Research in Area Studies: A Guide for Academic Libraries, (Oxford: Oxford University Press, 2015).

${ }^{20}$ Helen Hardacre, “Japanese Studies in the United States: Present Situation and Future Prospects," Asia Journal 1, no. 1, (1994): 32.
} 
On the other hand, Bangladesh has a strong political and economic partnership with Japan. Under this partnership framework, Japan has started its investment in Bangladesh in 1977 which is accelerated in the 1990s due to adopting economic liberalization policies by the Bangladesh government $(\mathrm{GoB})$. Though the amount of investment was quite small at the initial stage, it has increased over the years, particularly after the mutual visit of the Prime Ministers of the two countries in 2014. Now the Japanese have started showing interest in Bangladesh as their next investment destination due to several factors including the geo-strategic location of Bangladesh ${ }^{21}$, availability of natural resources, skilled human resources, rising middle-class people, and economic growth.

In terms of employability, besides the government one, these Japanese companies which are functioning all over the world could be another opportunity in pursuing jobs. Graduates can have their employment in any areas where actually social sciences graduates can apply. At the same time, employment opportunities in Japanese companies can provide an attraction to study Japan and the Japanese language, which is reflected in one of the IDI respondents' opinions. Based on the in-depth interview with one of the Japanese experts, Japanese companies prefer hiring Japanese thinking graduates.

Again, to meet the market demand and the $4^{\text {th }}$ industrial revolution (4IR), experts mainly emphasize industry-academia collaboration. Besides, the Japanese Studies program could be a bridge between industry-academia relations. According to one of the IDI respondents, "without the academiaindustry relationship, no discipline can really cater the need of the society as well as sustainability. This collaborative arrangement is not only limited to collaboration with Japanese organizations but also Japanese business as well as Bangladeshi organizations.

\section{Consolidation of Bilateral Relations}

Japan is a trusted friend of Bangladesh and the relationship between the two countries is absolutely time-tested and there have not been any so-called ups and downs between them. Since the liberation war, Japan has been providing continuous support to the development of Bangladesh ${ }^{22}$. Bangladesh and Japan are going to celebrate 50 years of bilateral relations in 2022 while the partnership between the two countries has reached a new height from government-to-government to people-to-people. Earlier, after the independence of Bangladesh, Bangabandhu Sheikh Mujibur Rahman has made tremendous efforts to strengthen Japan-Bangladesh ties. Recently, Bangladesh's Prime Minister Sheikh Hasina wishes to transform Bangladesh into another Japan during her visit to Japan in 2019.

In this connection, undoubtedly Japanese Studies department can play a crucial role in consolidating Japan-Bangladesh bilateral relations and fulfill the PM's wish. But the question is on how DJS plays such a critical role. In this regard, according to one of the IDI respondents, threedimension could be taken into consideration: a) policy formation where both the government would consider involving the department in formulating policies that can drive the relationship as well as trade, aid, and investment; b) scope for research where both governments should fund the department for further in-depth research so that the department can present policy briefs or policy guidance to the government and c) Japanese Studies department can play a critical role for the human resource development.

\footnotetext{
${ }^{21}$ Sheikh Shams Morsalin and Md. Saifullah Akon, "Japan Relocating Investments from China amid COVID-19: Opportunities for Bangladesh," The East Asian Studies Policy Brief, no. 3, 12 January 2021, https://drive.google.com/file/d/1LAwI1GIVNyk53D6haFJiQqXgbwZRKg5i/view

${ }_{22}$ Md. Saifullah Akon, Mahfujur Rahman, and Afnan Nur Bhuiyan, “Japan's Economic Cooperation with Bangladesh: An Appraisal," Social Science Review 36, no. 2, (2019): 216.
} 


\section{Policy Formulation}

One of the major prospectuses of the Japanese Studies program is its ability to have an impact on policy formulation at the micro-level. Japanese Studies program could hone one's research quality and helps to promote new ideas and thoughts at the policy level as well as enhancing knowledge in different think tanks. When the DJS graduates will work for the government, they will be important policymakers inside of the Bangladesh government. In that case, according to one of the IDI respondents from JETRO, if they know Japan very well, they can introduce the aspect of Japanese development into Bangladesh's policies. In this aspect, the Japanese Studies program could be an academic hub and help to promote Bangladesh's 'look east' policy.

On the other hand, Japan has been providing a good number of scholarships to Bangladeshi students under the auspices of continuous grants provided by the Ministry of Education, Culture, Sports, Science, and Technology (MEXT). Graduates from the Japanese Studies program have a better chance of receiving these scholarships as they are enriched with Japan-related knowledge and trained in the Japanese language. In this aspect, the recipients of Japanese scholarship can apply their knowledge in two different ways: first, they can play a key role in policy formulation by joining different policy level think tanks, and second, they will be able to use their Japan's experience in the development of Bangladesh.

\section{CHALLENGES OF JAPANESE STUDIES PROGRAMS}

Japanese Studies program, like all other academic disciplines of study, is confronted with substantial issues that must be addressed. The most significant obstacles to developing the Japanese Studies program as a discipline, in our opinion, can be divided into three major categories: 1) Lack of institutional enthusiasm, 2) Lack of resources, and 3) Financial constraint. The aforementioned major challenges are dealt with in detail in the following.

\section{Lack of Institutional Enthusiasm}

Since the very beginning, institutions are given scant incentives to promote and develop the Japanese Studies programs as a discipline. This scenario is sometimes common across the world. The treatment of area studies is seen as a data-driven industry by American institutions ${ }^{23}$. Scholars in different universities also show their non-cooperative attitudes towards developing area studies. Once Harumi Befu gave his proposal to establish 'World Association for Japanese Studies, but it was later highly criticized by Ian Reader, argues that: "By treating Japan as something sui generis rather than seeing what messages and meanings it can provide for the study of cultures in general, and for aspects of those cultures, such as religion and economic, we are increasing the likelihood that Japanese Studies will fail to become anything more than a glorified form of Japanology." ${ }^{24}$ On the other hand, some scholars of Bangladeshi institutions, mainly critics of Japanese Studies, focuses on more discussion on the political underpinnings, argue on the theoretical implications, employability opportunities, and existing resources in their respective universities.

\footnotetext{
${ }^{23}$ See also Paula R. Curtis, "Embracing the Rebirth of Japanese Studies," Association for Asian Studies, 18 May 2020 , https://www.asianstudies.org/embracing-the-rebirth-of-japanese-studies/; Maathias Basedu and Patrick Kollner, "Area Studies, Comparative Area Studies, and the Study of Politics: Context, Substance and Methodological Challenges," Zeitschrift fur Politikwissenschaft 1, no. 1, (2007): 108.

${ }^{24}$ Ian Reader, "Do we need more Japanese Studies - or less?," Japan Forum 7, no. 1, (2007): 109; Benjamin I. Schwartz, "Presidential Address: Area Studies as a Critical Discipline," The Journal Asian Studies 40, no. 1, (1980): 107-108.
} 
According to the findings of this study, some of the criticism is already obsolete. For example, in the case of area studies theory, according to Chansa-Ngavej ${ }^{25}$, area studies do not need their own specific theories per se. Area studies are already well-positioned to promote scientific understandings as the incorporation of several social sciences disciplines. Besides, several issues come forward to develop the new area-specific discipline. Educational institutions are aware of financial support and student's employability. As there is no area study-based jobs available in Bangladesh, academic institutions sometimes remain reluctant to develop the area studies department. Hardly any Bangladeshi institutions go beyond the stereotypical thinking of the education system. Despite being ample of opportunities and potentialities, Bangladeshi authorities and academic institutions simply did little to promote the Japanese Studies program as a discipline in their respective institution. As a result, sometimes, institutional negligence becomes one of the major obstacles to develop the Japanese Studies program in Bangladesh.

\section{Lack of Resources}

There is no substitute for adequate resources to establish a new academic discipline. In this case, two types of resources are required: material and human resources. Initially, Japanese Studies was a language-related study, which is now transformed from language to a multidisciplinary field under social science and humanities. Even, in South Asia, no university is providing degrees in Japanese Studies as a multidisciplinary field. Due to the traditional thinking of area studies or Japanese Studies, very little research was conducted in English. As a result, it is difficult to get available resources on Japanese Studies in the English language or get access to the resources that are published in English. Maximum initial resources of Japanese Studies or Japan-related study is in the Japanese language, which is sometimes difficult to understand by a non-Japanese reader. Production of necessary textbooks is also not to the mark. So, the Japanese Studies program suffers for its lack of material resources in Bangladesh.

On the other hand, the Japanese Studies program has also faced challenges due to the shortage of Japanologists as human resources, particularly in South Asia. Very few scholars are considered an expert on Japan or Japanese Studies. Besides, providing Japanese language training, Bangladesh is also facing a shortage of good language trainers. Language proficiency sometimes seems less imperative due to the global spread of English. Indeed, for the high quality of research on area studies, deep contextual knowledge and proficiency in relevant languages are necessary. As a pioneer of area studies in Bangladesh, the Department of Japanese Studies has started its journey as an independent and fully functioning department in 2017. Since it is a new department in this field, within few years the department will be able to produce true Japanologists. These Japan experts, according to one of the IDI respondents from JBCCI, will be able to play a crucial role in flourishing the Japanese Studies program in Bangladesh soon.

\section{Financial Constraint}

Financial constraints always put impediments to developing any kind of growth. Even producing quality education, financing is a must to provide a standard platform. In this regard, educational institutions hardly get proper financing, either from government or private sectors, to develop sustainable education or develop new academic disciplines. In Western countries, most of the area studies have been developed with the support of the private sector. According to one of the IDI respondents, one of the serious problems we face in Bangladesh is the lack of private sectors in supporting or promoting research and academic activities. They have recently come up with the sort

\footnotetext{
${ }^{25}$ Vee Chansa Ngajev and Kyu Young Lee, "Does Area Studies Need Theory? Revisiting the Debate on the Future of Area Studies," The Korean Journal of International Studies 15, no. 1, (2017): 86.
} 
of corporate responsibility program or social responsibility program. For any country, to be advance and to move forward, the private sector is supposed to support education first. But in Bangladesh, education is extremely neglected by the private sector.

Resources are now lying on the private sector because they actually contribute to the GDP. Unlike the 1970s or 1980s, the entire economy is at the hand of the private sector. If the private sectors do not come forward and they do not support the academic and research program, it is much difficult to establish a new discipline in this current period. In this regard, the academic institutions need to take initiatives to engage the private sectors in supporting the academic program as well as a research program. Such engagement of private sectors is the main difference between the countries who have introduced several areas with the private sectors support and stepping towards $4^{\text {th }}$ industrial revolution. $4^{\text {th }}$ industrial revolution is not only the matter of manufacturing or matter of economic activities, but it is also a matter of knowledge and matter of academic programs. If the private sectors do not come or the government does not realize the importance of academic and research programs that is really something that helps us much, Bangladesh will lack behind in producing the best graduates and competing globally.

\section{CONCLUSION AND RECOMMENDATION}

Japanese Studies, as an influential field of Area studies, spanning Japanese history, culture, society, literature, language, politics, governance, international affairs, economics, etc. Japanese Studies program represents the dynamics of knowledge, power, and pedagogy about Japan. As a pioneer of the area studies program, the Department of Japanese Studies can function as a hub of Japanese Studies in Bangladesh and contribute to global Japanese Studies by offering perspectives from Bangladesh. The DJS can act as a forerunner to support other universities to promote and develop new pedagogy and research.

In the present world, there had been lots of changes in regional and global politics where actually Bangladesh and Japan can work together and develop a sort of big game-changer framework based on win-win understanding. ${ }^{26}$ Besides, it is high time for Bangladesh to accommodate and apply new knowledge on its development process provided by Japanese Studies and other area studies disciplines. To make the 'look east policy' a success, Bangladesh needs to produce Japanologists to enhance its bilateral relations. In this regard, the Japanese Studies program could generate ample opportunities for both Bangladeshi and Japanese nationals pursuing higher studies both in Japan and Bangladesh. ${ }^{27}$ It is imperative to overcome the institutional and financial problems to develop the Japanese Studies program as a discipline in Bangladesh. However, to boost the Japanese Studies program in Bangladesh and enhance their cooperation and collaboration, the paper recommends some policies to both stakeholders:

\section{Recommendations to Bangladeshi Stakeholders}

Developing a new academic discipline is a daunting task for any academic institution as they have to face several challenges. To overcome those drawbacks, the Bangladesh government should understand the importance of area studies and enhance its enthusiasm to develop area studies or particularly Japanese Studies programs in different academic institutions. Besides, to fulfil the Prime Minister Sheikh Hasina's hope, the government should also accelerate its funding to the universities both to develop the new Japanese Studies discipline as well as promote the existing Japanese Studies

\footnotetext{
${ }^{26}$ Aung Shwe Prue Chodhury, "How They are Developing Us," in Meghna Guhathakurta and William van Schendel eds., The Bangladeshi Reader: History, Culture, Politics (London: Duke University Press, 2013), 454-455.

${ }^{27}$ Tuman J. P. and Strand J. R., “The role of mercantilism, humanitarianism, and Gaiatsu in Japan's ODA Programme in Asia," International Relations of the Asia Pacific 6, no. 1, (2006): 64.
} 
department in different frameworks i.e. policy formulation, policy implementation, research funding, and scholarship. Besides, the government could be act as a bridge for making cooperation between Japanese universities and Bangladeshi universities for joint research and teaching.

On the other hand, academic institutions, both public and private, can take the leading role in developing area studies or Japanese studies programs. They can accommodate more Japanese native professors in the universities could help to develop the Japanese Studies program. Besides, these Japanese professors could act as a bridge for deepening the Japan-Bangladesh bilateral relations. Besides, they should emphasize cooperation with other Bangladeshi and Japanese universities and industry-academia collaboration. For example, if the DJS can introduce some intensive program with Japanese companies in Bangladesh, it will help students more to collaborate between academics and industries. In this connection, according to one of the respondents of IDI from JETRO, they are happy to make collaborate with the DJS to develop more collaboration between academics and industry.

Furthermore, there is no alternative of resources. Without resources, no university can develop a different academic and research program. For that, universities need a very strong connection with the private sector. Here, for facilitating resources, private sectors involvement is mandatory. Besides, scholars on Japanese studies must think of Japanese language training for the better career of their students. As a pioneer of area studies, the DJS can be an academic hub to promote the Japanese Studies program. The DJS needs to operate more research activities and quality research programs that can contribute to making people understand the Japanese Studies program. Indeed, increasing awareness and showcasing highlights of the existing department and their prospects could help to understand people beyond their stereotypical thinking.

\section{Recommendations to Japanese Stakeholders}

Japan is a significant ally of Bangladesh and a trusted development partner as well. ${ }^{28}$ In addition to this bilateral proximity and economic partnership, Bangladesh is also important to Japan from a geostrategic point of view, particularly due to its location beside the Bay of Bengal. Bangladesh is becoming an economic hub in this region by connecting South Asia to Southeast Asia. Considering its strategic importance and economic growth, Japan has been expanding its business and cooperation to Bangladesh. Simultaneously, Bangladesh has also become a decisive part of the Asia-Pacific region to implement Japan's new Free and Open Indo Pacific (FOIP) policy and to make Quadrilateral Security Dialogue (QUAD) effective. ${ }^{29}$ To accelerate the pace of investment, Japan also needs Japanologists who can uphold Japan while competing with other competitors i.e. China. In this regard, Japan, particularly Japan Embassy and Japan Foundation need to enhance its further cooperation and collaboration to develop the new Japanese Studies program and provide adequate funds to expand the scope of the existing Japanese Studies program in Dhaka University.

Currently, the Japan Foundation is providing book support, faculty development, and funding research and student exchange programs. Though this support is a big leap forward for developing the Japanese Studies program in Bangladesh, the JF can think of being connected more with other universities. Japan Foundation can open its regional office in Bangladesh to work with Bangladeshi educational institutions more closely. In addition, other Japanese stakeholders including JICA, JETRO, JBCCI, and other Japanese companies should also enhance their engagement with academic institutions and provide funding for Japan-related research.

On the other hand, the cohort among the younger generations who are studying Japan has common aplomb to visit Japan or to work in a Japanese company. In this regard, Japan Embassy might increase the number of scholarships including MEXT and intensifying other exchange programs for

\footnotetext{
${ }^{28}$ See also Chowdhury M. H. "Japan-Bangladesh Relations: A Review of Development Partnership," International Studies 45, no. 1, (2006): 1-21

${ }^{29}$ Johannes Plagemann "Small States and Competing Connectivity Strategies: What Explains Bangladesh's Success in Relations with Asia's Major Power," The Pacific Review, (2021), https://doi.org/10.1080/09512748.2021.1908410
} 
Japanese Studies students. ${ }^{30}$ Besides, Japanese companies might hire Japanese Studies graduates as they are capable both in the Japanese language and other departments. However, the cooperation and collaboration between the two stakeholders could enhance sustainable bilateral relations through developing the Japanese Studies program and promoting Japanologists-a true flag bearer of Japan.

\section{ACKNOWLEDGEMENT}

The authors would like to show his gratitude to WIJEAS' anonymous reviewers and their constructive feedbacks in improving the quality of the manuscript. We are also immensely for their comments on earlier versions of the draft. No potential conflict of interest was reported. This research received no specific grant from any funding agency in the public, commercial or not-for-profit sectors.

${ }^{30}$ Imtiaz Ahmad, "Foreign Policy," in Alia Riaz and Mohammad Sajjadur Rahman eds., Routledge Handbook of Contemporary Bangladesh (London: Routledge, 2016), 369. 


\section{REFERENCES}

Ahmad, Imtiaz, "Foreign Policy," in Alia Riaz and Mohammad Sajjadur Rahman eds., Routledge Handbook of Contemporary Bangladesh (London: Routledge, 2016), 369-388.

Akon, Md. Saifullah, Mahfujur Rahman, and Afnan Nur Bhuiyan, “Japan's Economic Cooperation with Bangladesh: An Appraisal,” Social Science Review 36, no. 2, (2019): 215-232.

Alam, Mohammed Ansarul, "An Overview of Japanese Language Education in Bangladesh from the Perspective of Recent Progress in Japanese Language Education In South Asia," Journal of the Institute of Modern Languages 23, (2012): 17-29.

Alam, Mohammed Ansarul, "JLE in Bangladesh-Recent Development and Challenges," in Arun Shyam ed., Japanese Language Education in South Asia: Issues and Challenges, (Dhaka: EFL University Publication, 2020), 18-22.

Alam, Mohammed Ansarul, "Significance of Proper Information in Learning Japanese Language: Focusing on the Gap between Learners and Reality," Journal of the Institute of Modern Languages 29, (2019): 19-33.

Basedu, Maathias, and Patrick Kollner, "Area Studies, Comparative Area Studies, and the Study of Politics: Context, Substance and Methodological Challenges," Zeitschrift fur Politikwissenschaft 1, no. 1, (2007): 105-124.

Bates, Robert H., "Area studies and Political Science: Rupture and Possible Synthesis," Africa Today, Vol. 44, No. 2, 1997, pp. 123-132.

Boyce, Carolyn, and P. Neale, "Conducting in-depth Interviews: A Guide for Designing and Conducting In-Depth Interviews for Evaluation Input," Pathfinder International, 15 May 2006, https://donate.pathfinder.org/site/DocServer/m e tool series indepth interviews.pdf;jsessioni $\mathrm{d}=00000000$. app20015b?NONCE_TOKEN=15965777B6F9B194066D1C6E161E9EE0

Breakwell, Glynis M., Interviewing: Problems in Practice, (London: Blackwell, 1990).

Chansa-Ngavej, Vee, and Kyu Young Lee, "Does Area Studies Need Theory? Revisiting the Debate on the Future of Area Studies,” The Korean Journal of International Studies, vol. 15, no. 1, 2017, pp. 85-101.

Chodhury, Aung Shwe Prue, "How They are Developing Us," in Meghna Guhathakurta and William van Schendel eds., The Bangladeshi Reader: History, Culture, Politics (London: Duke University Press, 2013), 454-456

Chowdhury, M. H., "Japan-Bangladesh Relations: A Review of Development Partnership," International Studies 45, no. 1, (2006): 1-21.

Curtis, Paula R., "Embracing the Rebirth of Japanese Studies," Association for Asian Studies, 18 May 2020, https://www.asianstudies.org/embracing-the-rebirth-of-japanese-studies/;

Gaitanidis, Ioannis, "Critique of/in Japanese Studies: An Introduction to the Special Issue", (paper presented at the British Association for Japanese Studies Conference, Chiba University, Japan, 27-28

May

2017),

https://www.researchgate.net/publication/332142994_Critique_ofin_Japanese_Studies_An_Int roduction_to_the_Special_Edition

Gaitanidis, Ioannis, “Jobbing as Methodology: Victor T. King's Involvement with Area Studies and Some Implications for Japanese Studies and Beyond," in Arun Shyam ed., Boneo and Sulawesi: Indigenous Peoples, Empires and Area Studies, (London: Routledge, 2019), 176-193.

Hardacre, Helen, "Japanese Studies in the United States: Present Situation and Future Prospects," Asia Journal 1, no. 1, (1994): 17-36.

Japan Foundation (JP), Survey Report on Japanese-Language Education Abroad 2015, (Tokyo: JF, 1990).

Kennedy, Michael D., "Globalizing Knowledge Through Area Studies," The Journal of the International Institute 9, no. 1, (2001): 12-13. 
Khan, Shabir Ahmad, “Area studies : Nature and Scope,” Central Asia Journal 82, no. 2, (2018,): 131142.

Mehler, Andreas, "Comparative Area Studies," in Matthias Middell ed., The Routledge Handbook of Transregional Studies, (London: Routledge, 2018), 167-73.

Miyoshi, Masao, and H. D. Harootunian, eds., Learning places: The afterlives of area studies, Durham: Duke University Press, 2002.

Morsalin, Sheikh Shams, and Md. Saifullah Akon, "Japan Relocating Investments from China amid COVID-19: Opportunities for Bangladesh," The East Asian Studies Policy Brief, no. 3, 12 January 2021 https://drive.google.com/file/d/1LAwI1GlVNyk53D6haFJiQqXgbwZRKg5i/view

Petersson, Bo, "We Don't Do Areas Studies: Reflections on the Development of the Genre of Research from a Political Science Perspective," Forum of EthnoGeoPolitics 3, no. 2, (2015): 37-48.

Pitman, Lesley, Supporting Research in Area Studies: A Guide for Academic Libraries, (Oxford: Oxford University Press, 2015).

Plagemann, Johannes, "Small States and Competing Connectivity Strategies: What Explains Bangladesh's Success in Relations with Asia's Major Power," The Pacific Review, (2021), https://doi.org/10.1080/09512748.2021.1908410

Reader, Ian, "Do we need more Japanese Studies - or less?," Japan Forum 7, no. 1, (2007): 107-112.

Sato, Jin, "Research at a Distance: Area Studies in the Post-Pandemic Era," International Journal of Asian Studies 17, no. 2, (2020): 105-108.

Schwartz, Benjamin I., "Presidential Address: Area Studies as a Critical Discipline," The Journal Asian Studies 40, no. 1, (1980): 107-108.

Sil, Rudra, "The Survival and Adaptation of Area Studies," in Dirk Berg-Schlosser, Bertrand Badie and Leonardo Morlino eds., The SAGE Handbook of Political Science, (London: SAGE Publication, 2020), 255-271.

Tuman, J. P., and Strand J. R., "The role of mercantilism, humanitarianism, and Gaiatsu in Japan's ODA Programme in Asia," International Relations of the Asia Pacific 6, no. 1, (2006): 61-80

Wun'Gaeo, Surichai, “Japanese Studies in Southeast Asia: Problematic Trends and Challenges Ahead", (paper presented at the Kyoto Conference on Japanese Studies, Kyoto, Japan, 25 March1996): 169178. 